\title{
CONCEPÇÕES E TENDÊNCIAS PEDAGÓGICAS DA EDUCAÇÃO FÍSICA: CONTRIBUIÇÕES E LIMITES
}

GONÇALVES, Vivianne Oliveira - Mestre em Educação Física/UNICAMP - Docente EF/ CAJ/UFG. nanifef@hotmail.com

RESUMO: Este texto procura construir uma breve análise das concepções e tendências pedagógicas da educação física nos anos 80, em face do momento histórico em que foram construídas. Apresenta, portanto, como preocupação central, identificar e discutir as contribuições e limites de tais tendências, considerando a sua historicidade e o fato de o movimento dos anos 80 ter o mérito de anunciar e ser portador de um novo agir e pensar a educação física brasileira.

Palavras - chave: Educação Física - Concepções Pedagógicas.

ABSTRACT: This text looks for to build a brief analysis about pedagogical conceivings and tendencies of the physics education in 80's, face of the historical moment in which it was built. It shows, therefore, as main concern, to identify and to discuss the contributions and limits of that tendencies, considering its historicity and the fact of 80's movements have the merit of to announce and to be porter of a new way of to act and to think the brazilian physics education.

Key-words: Physic - Education - Pedagogical - Conceivings.

\section{Introdução}

Sem dúvida alguma, as diferentes e crescentes propostas que vêm sendo construídas nos últimos vinte anos no campo da Educação Física trouxeram importantes contribuições para o constante repensar sobre a prática pedagógica, entendendo que esta deve vir acompanhada da teoria da Educação, que lhe sustenta e lhe dá sentido.

Assim, pretendo aqui refletir acerca das concepções pedagógicas da educação física construídas a partir dos anos 80 , buscando identificar e discutir as contribuições e limites de tais tendências e considerando o momento histórico, social e político em que as mesmas emergiram. Ressalto, ainda, que o presente artigo não tem a pretensão de dizer qual tendência é melhor ou pior, e sim promover o debate, na medida em que considero que, apesar dos avanços neste âmbito, ainda existe a necessidade de discussão acerca dos conteúdos da educação física, cuja manifestação transcende ao universo da escola, mas estabelece com esta vínculos determinantes.

\section{Concepções e Tendências Pedagógicas da Educação Física: contribuições e limites}

A partir do final dos anos 70 e início da década de 80 construiu-se, na educação física brasileira, um conjunto de concepções pedagógicas que buscavam visualizar outros motivos justificadores da presença da educação física na escola, que não aquele centrado no eixo paradigmático da aptidão física. Neste artigo, procuro refletir acerca das concepções e tendências pedagógicas da educação física nos anos 80. Porém, esse refletir abrange também a consideração do momento histórico em que elas emergiram. Assim, apresento, inicialmente, o contexto histórico em que se dá a construção dessas concepções para, posteriormente, abordálas e, por fim, tecer algumas considerações acerca de suas contribuições e limites. 
DAÓLIO (1997) afirma que, a partir do momento em que se iniciaram os cursos de pós-graduação na área da Educação Física, o regresso dos primeiros brasileiros doutorados no exterior e a busca por cursos de pós-graduação em outras áreas, sobretudo nas ciências humanas, começou a haver mais explicações científicas para a educação física, além de um aumento significativo de publicações, eventos e congressos na área.

Já CAPARRÓZ (1996) afirma que o movimento que surgiu na educação física na década de 80 foi decorrente de dois fatores: o momento sócio-político da sociedade brasileira e o processo de redemocratização do país, e a necessidade da área de qualificação. Assim, a efervescência política e social por que passava o Brasil se traduzia, no campo educacional, por um cenário de lutas contra a tecnologia educacional, implementada pela ditadura pós-64. Portanto, posicionar-se contra o tecnicismo demandava adotar uma postura crítica diante dos pressupostos positivistas que davam sustentação a essa pedagogia. Por isso, os educadores brasileiros buscavam, na fenomenologia e no marxismo, instrumentos para essa luta. Foi nesse contexto que surgiram as várias correntes pedagógicas da educação física.

Apesar de concordar com DELLA FONTE (2001) em relação ao perigo de se classificar a produção acadêmica no período, no sentido de sua rigidez diante da complexidade do real, cito a classificação elaborada por CASTELLANI FILHO (1999), que as localiza, no que se refere à metodologia de ensino, em não-propositivas e propositivas. Em relação às não-propositivas, encontram-se as abordagens Fenomenológica (Silvino Santin e Wagner Wey Moreira), a Sociológica (Mauro Betti) e a Cultural (Jocimar Daólio). No campo das propositivas, detecta-se a presença das não-sistematizadas e das sistematizadas. $\mathrm{Na}$ primeira, situam-se as concepções Desenvolvimentista (Go Tani), Construtivista (João Batista Freire), Crítico-emancipatória (Elenor Kunz), Plural (Jocimar Daólio), e de Aulas Abertas (Hildebrandt e Langing). Na segunda, situam-se a da Aptidão Física e a Crítico-superadora, esta assinada por um Coletivo de Autores.

Faço um parêntese, citando, ainda, algumas das principais referências a ganhar destaque entre os profissionais de educação física, como a Psicomotricidade e a perspectiva humanista, apesar do viés da psicologia presente em ambas. Os fundamentos da Psicomotricidade foram defendidos em contraposição às perspectivas do rendimento motor e esportivização da educação física. Embora não tenha se consolidado como uma tendência, a Psicomotricidade contribuiu com a educação física, ao mostrar a importância do desenvolvimento das estruturas psicomotoras de base. Já a "Educação Física Humanista”, de Vítor Marinho de Oliveira, trouxe para a área o debate diretividade x não-diretividade, 
opondo-se à visão fragmentada do comportamento humano, à ênfase no ensino esportivo e aos seus fundamentos psicológicos baseados no comportamentalismo.

Retomo, agora, a classificação elaborada por CASTELLANI FILHO (1999), apresentando as abordagens não-propositivas, ou seja, a fenomenológica, a sociológica e a cultural. A primeira, representada por Wagner Wey Moreira, preocupa-se com o fenômeno da corporeidade, utilizando a contribuição de Merleau-Ponty. Refuta o mecanismo tradicional, propondo-se a olhar para a educação física e para o corpo, procurando compreender seu significado. Nessa abordagem, o conceito de corporeidade ganha destaque, pois é o corpo que vincula o ser no mundo, entendido como fonte de experiências significantes, permitindo compreender a indissociabilidade entre o sujeito e o objeto.

Já a abordagem sociológica ou sistêmica, elaborada por Mauro Betti, sofreu influências de estudos na área da sociologia, da filosofia e, em menor grau, da psicologia. Betti considera a teoria dos sistemas como um instrumento e um modo de pensar o currículo de educação física. Esta é entendida por ele como um sistema hierárquico aberto. Hierárquico porque interage com níveis superiores, como o macrossocial, o sistema educacional e o escolar que, nesta ordem, influenciam do mais geral para o mais particular, até alcançar a educação física. Aberto porque a educação física sofre influência do meio social, mas também o influencia.

Betti concebe seu modelo segundo polaridades, cujos extremos envolvem variáveis sócio-psicológicas e variáveis didático-pedagógicas. Assim, por exemplo, no caso das variáveis didático-pedagógicas teríamos, nos estilos de ensino, o comando e a resolução de problemas representando extremos. A educação física, por influência do militarismo, utilizou o comando, mas, para os discursos emergentes, a resolução de problemas seria mais viável. Por essa perspectiva, o autor vislumbra alternativas de mudanças, já que alguns pólos têm prevalecido ao longo da história da educação física. Nessa abordagem, é ressaltada, ainda, a preocupação em garantir a especificidade da área, na medida em que o binômio corpo/movimento é considerado como meio e fim da educação física escolar.

Dentre as contribuições do modelo apresentado por Betti, DARIDO (1998) destaca dois princípios: o da não-exclusão, segundo o qual nenhuma atividade pode excluir qualquer aluno, e o da diversidade, ao propor atividades diferenciadas. Apontando as limitações, FERREIRA (1999) alerta para o fato de que a teoria dos sistemas afasta Betti da tradição pedagógica crítica, já que em seu modelo parece não haver lugar para a luta de classes e sim para interações simbólicas. 
Quanto à abordagem cultural, de Jocimar Daólio, esta originará a Plural, agrupada no campo das propositivas, a qual será abordada neste momento. A abordagem de educação física Plural é resultado das incursões do autor no campo da Antropologia Social, influenciado por Mauss, Geetz, entre outros. Nesta, o movimento é entendido enquanto manifestação da cultura própria, definida pela história do corpo e vivências de cada um. $\mathrm{O}$ autor acredita que a educação física, ao buscar a eficiência técnica, desconsiderou as maneiras como os alunos lidam com as formas de ginástica, jogos e lutas. Nesse sentido, trabalha para que as diferenças entre os alunos sejam percebidas, valorizando-as independentemente de um modelo certo ou errado. Sendo assim, a condição mínima é de que as aulas atinjam todos os alunos. Para tanto, o professor deve eleger, com os alunos, as atividades valorizadas culturalmente naquele grupo, para então, proporcionar a base motora que permita a ele, compreender, usufruir, criticar e transformar os elementos da cultura corporal.

Ainda no campo das propositivas não-sistematizadas, encontram-se as concepções desenvolvimentista, construtivista, crítico-emancipatória e de aulas abertas. O modelo desenvolvimentista é explicitado, no Brasil, nos trabalhos de Go Tani, cuja obra mais representativa é "Educação física escolar: fundamentos de uma abordagem desenvolvimentista". Dirigida para crianças de 4 a 14 anos, busca nos processos de aprendizagem e desenvolvimento uma fundamentação para a educação física escolar. É uma tentativa de caracterizar a progressão normal do crescimento físico, do desenvolvimento fisiológico, motor, cognitivo e afetivo-social e, em função disso, sugerir elementos relevantes para a estruturação dessa área de conhecimento.

O objetivo principal da educação física nessa abordagem é oferecer experiências de movimento adequadas ao nível de crescimento e desenvolvimento, ou seja, adequar os conteúdos ao longo das faixas etárias. Além disso, os conteúdos devem ser desenvolvidos segundo uma ordem de habilidades, das mais simples para as mais complexas.

A afirmação - e que talvez mais tenha gerado críticas a essa concepção - é que o objeto de estudo e aplicação da educação física é o movimento humano, e que a especificidade da educação física, nas séries iniciais, é promover a aprendizagem do movimento. Esta afirmação é criticada pelo reducionismo biológico, por não considerar as implicações sociais da educação física. A pouca importância ou limitada discussão acerca da influência do contexto sócio-cultural é uma das limitações dessa abordagem, no entanto, merece destaque a preocupação com a garantia da especificidade da área, e a valorização do conhecimento sobre as necessidades dos alunos nas diferentes faixas etárias, também reconhecida na proposta do Coletivo de Autores. 
Já a proposta construtivista tem como representante João Batista Freire, cujo livro "Educação de Corpo Inteiro" teve papel determinante na divulgação das idéias construtivistas na educação física. A proposta é apresentada como uma opção metodológica, em oposição às linhas mecanicistas e propõe a valorização do conhecimento espontâneo dos jogos, brincadeiras e atividades motoras que a criança possui - sua cultura infantil - muitas vezes negada pela escola. O jogo é considerado o principal conteúdo/estratégia do ensino, pois, quando joga ou brinca, a criança aprende.

A principal vantagem dessa abordagem, segundo DARIDO (1998), é que ela possibilita uma maior interação com uma proposta pedagógica ampla de educação física nas séries iniciais. Tem, ainda, o mérito de levantar a questão da importância da educação física na escola ao considerar o conhecimento que a criança já possui e propor uma alternativa aos métodos diretivos. Porém, desconsidera a especificidade da educação física, na medida em que o movimento é visto, muitas vezes, como instrumento para facilitar a aprendizagem de conteúdos ligados ao aspecto cognitivo.

A concepção crítico-emancipatória, de Elenor Kunz, por sua vez, está centrada no ensino dos esportes, buscando uma ampla reflexão sobre o mesmo. Nesse sentido, indica a necessidade de instrumentalização dos alunos com conhecimentos que possibilitem não apenas a sua prática, mas o diálogo e a compreensão da complexidade do mundo esportivo (social, político, econômico e cultural). Busca contrapor a uma prática dominadora, opressiva e alienante, a concepção dialógica do se-movimentar, resgatando a cultura infantil, a dialogicidade e a problematização. Para a construção desse processo, o autor propõe três etapas: a investigação temática (realização espontânea de movimentos), a problematização e crítica, e o processo de reflexão-ação, ou seja, compreender o mundo pela ação. Destaca-se, nessa concepção, a valorização do mundo do aluno, bem como as participações deste nas decisões de ensino, além do processo de crítica, re-elaboração e transformação do esporte de rendimento, ainda tão presente nas aulas de educação física.

Quanto à concepção de ensino de aulas abertas, observa-se que foi desenvolvida na Alemanha por Hildebrandt e Langing, e estudada e adaptada no Brasil pelo grupo de trabalho pedagógico das Universidades Federais de Pernambuco e Santa Maria. Tem como princípio geral a abertura e participação dos alunos nas decisões referentes ao processo ensinoaprendizagem, desde os objetivos, seleção dos conteúdos, metodologia e avaliação. Assim, o espaço da aula serve para construir o conteúdo e os métodos de ensino visam estimular a ação dos alunos na resolução de problemas, baseando-se em suas experiências anteriores, tendo como características a não-diretividade, o ensino por descobertas, a elaboração de exercícios, 
a organização das aulas, entre outros. O professor aparece, dessa forma, como mediador entre o aluno e o conhecimento, sendo aquele responsável também pela aula.

Por fim, no universo das concepções propositivas sistematizadas localizam-se duas concepções: a da aptidão física e a crítico-superadora. As idéias da concepção referente à aptidão física relacionadas à saúde estiveram presentes ao longo da história da educação física brasileira e, mais recentemente, são difundidas por autores como Nahas e Guedes. Essa concepção reabre a discussão sobre os conceitos de estilo de vida, com vistas a contribuir para a melhoria da saúde e da qualidade de vida da população. Assim, cumpre à educação física escolar criar, nos alunos, o prazer e o gosto pelo exercício e pelo desporto, que é redimensionado, ou seja, não basta que os alunos dominem técnicas ou regras, mas que saibam como realizar essas atividades com segurança e eficiência, o que tornam necessários os conhecimentos acerca da fisiologia, biomecânica, nutrição e anatomia. Dessa forma, os conteúdos da educação física escolar abrangem a saúde, freqüência cardíaca, avaliação física, respiração, alimentação, lesões esportivas, entre outros.

Uma das mais contundentes críticas a esse discurso, segundo FERREIRA (2001), está no caráter individual de suas propostas, ou seja, apresenta o indivíduo como o problema e a mudança de estilo de vida como a solução. Mas o fato é que vivemos em uma sociedade dividida em classes sociais, na qual nem todas as pessoas têm condições econômicas para adotar um estilo de vida saudável. Assim, essa concepção deve ser questionada, na medida em que desconsidera a necessidade de luta por mudanças concorrentes no ambiente social e econômico.

Em oposição ao modelo mecanicista, da aptidão física, elaborou-se a concepção crítico-superadora. O trabalho marcante dessa concepção foi publicado com o título "Metodologia do ensino da educação física", escrito por um coletivo de autores. Esta utiliza o discurso da justiça social como ponto de apoio e é baseada no marxismo e neo-marxismo, tendo recebido influência de Libâneo e Saviani.

Esta concepção acredita que qualquer consideração sobre a pedagogia deve versar, não somente sobre como ensinar, mas também sobre como adquirimos estes conhecimentos, valorizando a contextualização dos fatos e o resgate histórico. É diagnóstica, porque pretende ler os dados da realidade, interpretá-los e emitir um juízo de valor; é judicativa, porque julga os elementos da sociedade a partir de uma ótica de classe; e é teleológica, pois busca uma direção, numa perspectiva de classe social. Essa reflexão pedagógica é compreendida como sendo um projeto político-pedagógico. 
Quanto à seleção dos conteúdos para as aulas de educação física, propõe que se considere a relevância social dos mesmos, sua contemporaneidade e sua adequação às características sócio-cognitivas dos alunos. Condena o ensino por etapas e adota a simultaneidade na transmissão, ou seja, os mesmos conteúdos devem ser trabalhados de maneira mais aprofundada ao longo das séries. A educação física é entendida como uma disciplina que trata da cultura corporal, que tem como temas o jogo, a ginástica, o esporte, a capoeira, entre outros.

Essa concepção tem nos alertado sobre a importância da educação e da educação física contribuírem para que as mudanças sociais possam ocorrer, diminuindo as desigualdades e as injustiças sociais. No entanto, críticas são feitas a ela no sentido de não haver propostas efetivas. DARIDO (1997), observando a prática pedagógica de professores de educação física, percebe que estes sentem a falta de elementos para trabalharem essa proposta na prática concreta.

Tendo apontado as concepções e tendências da educação física de forma geral, devido às limitações deste texto, ressalto a importância de se considerar o contexto histórico em que foram elaboradas, no sentido de não perder sua historicidade. Para DELLA FONTE (2001), a perda da historicidade em relação a essas concepções tem sido demonstrada pela oscilação entre dois pólos: a idolatria e a condenação em decorrência de seus limites. O processo de idolatria verifica-se quando se toma a produção dos anos 80 como não passíveis de questionamentos, como se a história da educação física começasse ali. No entanto, não haveria chance do movimento dos anos 80 constituir sua identidade, se não tivesse assumido uma postura de negatividade com o passado, sem que isso resultasse no abandono absoluto desse passado.

A produção teórica dos anos 80 tem recebido, também, inúmeras críticas por não apresentar uma proposta de intervenção sistematizada, assim como fundamentos teóricos consistentes para a ação pedagógica. No entanto, há de se levar em conta o fato de que a educação brasileira da época, de um modo geral, elegeu a análise dos determinantes sócioeconômicos e políticos como foco central de suas discussões. Segundo CASTELLANI FILHO (citado por DAÓLIO, 1997), o debate dos anos 80 foi mais político que acadêmico, porque o momento exigia denúncias de uma sociedade que se queria modificar. Só a partir da segunda metade dos anos 80 , houve a necessidade acadêmica de construção do novo.

Não se trata, portanto, de considerar uma concepção melhor ou pior, pois, a medida em que são diferentes, defendem projetos educacionais diferentes e até mesmo divergentes. Trata-se de reconhecer que o movimento vivido nos anos 80 tem o mérito de anunciar e ser 
portador de um novo agir e pensar a educação física. Um movimento que é atual, sendo que temos a possibilidade de olhar o passado, aproveitar os avanços e superar as limitações.

\section{Referências Bibliográficas}

CAPARRÓZ, F. E. A educação física como componente curricular: entre a educação física na escola e a educação física da escola. Dissertação (Mestrado em História e Filosofia da Educação) Pontifícia Universidade Católica de São Paulo, 1996.

CASTELLANI FILHO, L. A educação física no sistema educacional brasileiro: percurso, paradoxos e perspectivas. Tese (Doutorado em Educação) Faculdade de Educação, Universidade Estadual de Campinas, 1999.

DAÓLIO, J. Educação física brasileira: seus autores e atores. Tese (Doutorado em Educação Física) Faculdade de Educação Física, Universidade Estadual de Campinas, 1997.

DELLA FONTE, S. S. O passado em agonia: da criação dos reducionismos ou sobre como matar a historicidade. In: CAPARRÓZ, F. E. (Org.). Educação física escolar: política, investigação e intervenção. Vitória: Proteoria, 2001.

DARIDO, S. C. Apresentação e análise das principais abordagens da educação física escolar. Revista Brasileira de Ciências do Esporte, n. 1, vol. 20, setembro/1998.

FERREIRA, M. G. A teoria/concepção sistêmica: uma perspectiva crítica na pedagogia da educação física. Revista Pensar a Prática, vol. 3, jun/jul. 1999.

FERREIRA, M. S. Aptidão física e saúde na educação física escolar: ampliando o enfoque. Revista Brasileira de Ciências do Esporte, n. 2, vol. 22, janeiro/2001. 